\title{
Flight Test Results from the NF-15B Intelligent Flight Control System (IFCS) Project with Adaptation to a Simulated Stabilator Failure
}

\author{
John T. Bosworth* and Peggy S. Williams-Hayes $\dagger$ \\ NASA Dryden Flight Research Center, Edwards, California, 93523
}

\begin{abstract}
Adaptive flight control systems have the potential to be more resilient to extreme changes in airplane behavior. Extreme changes could be a result of a system failure or of damage to the airplane. A direct adaptive neural-network-based flight control system was developed for the National Aeronautics and Space Administration NF-15B Intelligent Flight Control System airplane and subjected to an inflight simulation of a failed (frozen) (unmovable) stabilator. Formation flight handling qualities evaluations were performed with and without neural network adaptation. The results of these flight tests are presented. Comparison with simulation predictions and analysis of the performance of the adaptation system are discussed. The performance of the adaptation system is assessed in terms of its ability to decouple the roll and pitch response and reestablish good onboard model tracking. Flight evaluation with the simulated stabilator failure and adaptation engaged showed that there was generally improvement in the pitch response; however, a tendency for roll pilot-induced oscillation was experienced. A detailed discussion of the cause of the mixed results is presented.
\end{abstract}

\section{Nomenclature}

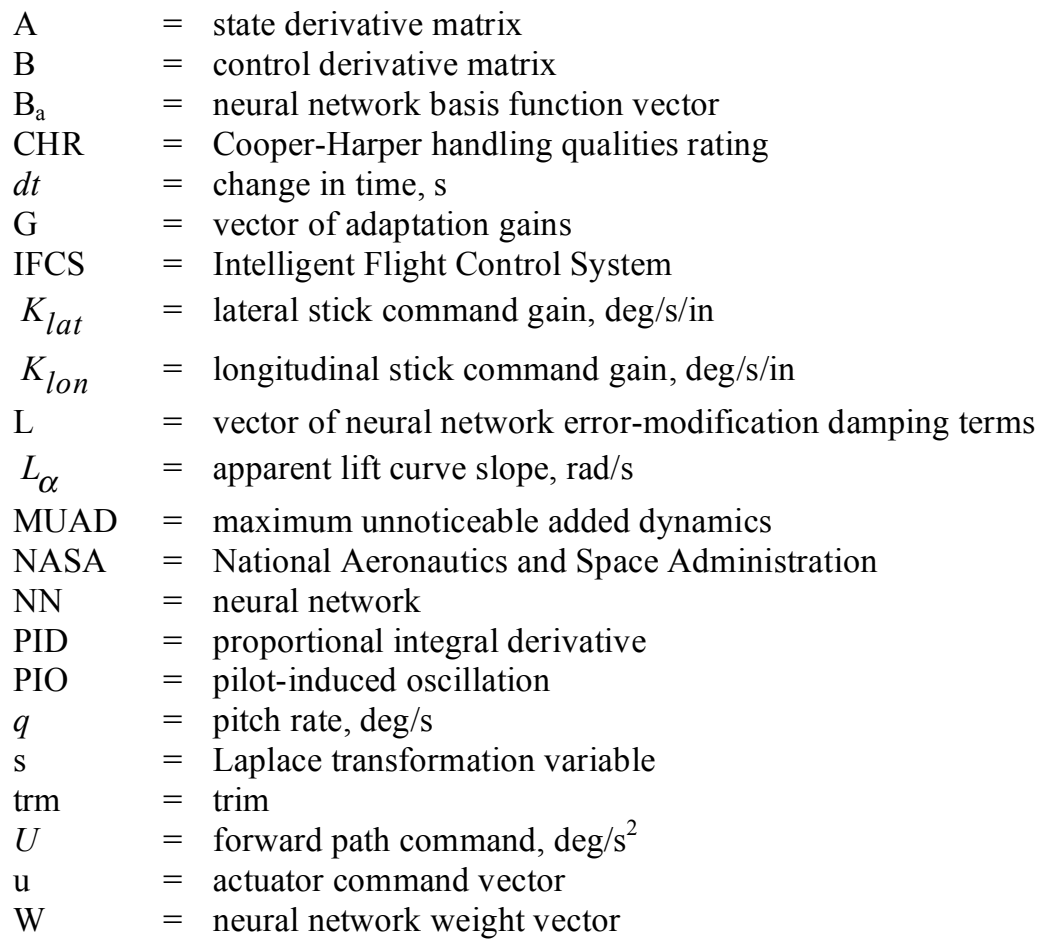

\footnotetext{
* Aerospace Engineer, Controls and Dynamics Branch / RC, NASA Dryden Flight Research Center, P.O. Box 273, MS D-4840, AIAA Senior Member.

${ }^{\dagger}$ Aerospace Engineer, Controls and Dynamics Branch / RC, NASA Dryden Flight Research Center, P.O. Box 273, MS D-4840, AIAA Member.
} 


$$
\begin{array}{ll}
\mathrm{WPn} & =\text { roll axis neural network weight for input } \mathrm{n} \\
\mathrm{WQn} & =\text { pitch axis neural network weight for input } \mathrm{n} \\
\mathrm{WRn} & =\text { yaw axis neural network weight for input } \mathrm{n} \\
\dot{W} & =\text { neural network weight vector derivative } \\
\mathrm{x} & =\text { state vector } \\
\dot{x} & =\text { state vector derivative } \\
\delta_{s t k} & =\text { pilot stick position, in. } \\
\zeta_{S p} & =\text { short period damping } \\
p & =\text { roll rate, deg/s } \\
\tau_{r} & =\text { roll mode time constant, } \mathrm{s} \\
\omega_{s p} & =\text { short period natural frequency, } \mathrm{rad} / \mathrm{s}
\end{array}
$$

$\begin{array}{ll}\text { Subscripts } & \\ \text { ad } & =\text { adaptation } \\ \text { c } & =\text { command } \\ \text { dd } & =\text { feedback } \\ \text { err } & =\text { error compensation } \\ \text { lat } & =\text { lateral } \\ \text { lon } & =\text { longitudinal } \\ \text { ref } & =\text { reference } \\ \text { stk } & =\text { stick }\end{array}$

\section{Introduction}

daptive flight control systems have the potential to be more resilient to extreme changes in airplane behavior. A Extreme changes could be a result of system failure or a result of damage to the airplane: an example of this type of change is a frozen (unmovable) flight control surface. The resulting change in vehicle dynamics causes a degraded response to commands and a coupling between the longitudinal and lateral-directional dynamics. An adaptive flight control system has the potential to adjust for failure or damage to maintain control in flight and provide handling qualities that allow for safe recovery of the airplane.

The National Aeronautics and Space Administration (NASA) Dryden Flight Research Center (DFRC) (Edwards, California) NF-15B Intelligent Flight Control System (IFCS) airplane was equipped with a neuralnetwork-based adaptive flight control system. The system was implemented as a direct adaptive system; in this scheme, the adaptation is driven by the presence of feedback errors and no explicit model identification or prior knowledge of the cause of the errors is required.

A simulated stabilator failure mode was developed as a test for the IFCS. The NASA NF-15 IFCS airplane, tail number 837 (NASA 837), is shown in Fig. 1. The stabilator surfaces provide the majority of the control power for both pitch and roll control. Disabling by immobilization (freezing) one of these control surfaces causes a significant change in vehicle dynamic behavior. For example, with this failure, a pitch command results in half of the expected pitching moment and generates a significant rolling moment.

The direct adaptive system attempts to reestablish good handling qualities based on the sensed errors caused by the simulated stabilator failure. A formation flight handling qualities task was flown with the simulated failures. The handling qualities were evaluated with no failure, with the simulated failure, and finally with the simulated failure and adaptation.

This report presents the flight results. Comparisons are made with the simulation predictions. The behavior of the adaptation system is presented with analysis of its ability to provide good handling qualities in the presence of the simulated stabilator failure.

\section{Background}

\section{A. Description of the Test Airplane}

The test airplane, NASA 837 (Fig. 1), is a highly-modified preproduction F-15B airplane and is not representative of production F-15 aircraft. Modifications to the airplane include two canards mounted on the upper inlet area forward of the wing. The canards are modified F-18 horizontal tail surfaces, and their position in flight is scheduled to respond with angle of attack. An additional modification to the airplane is the incorporation of the 
F100-PW-229 Pratt \& Whitney (West Palm Beach, Florida) engines equipped with axisymmetric thrust-vectoring nozzles. The thrust-vectoring capability was not used during the flight phase covered by this report. The airplane is controlled by a quadruplex, digital, fly-by-wire flight control system. All mechanical linkages between the control stick, rudder pedals, and control surfaces have been removed from the airplane. ${ }^{1}$ A third processor was added to each of the flight computer boxes to execute experimental control laws in a redundant safety-critical mode. A more capable single-string research processor was added to execute the neural network software. Limits and safety monitors exist in the flight-critical control law processor to ensure safe operation.

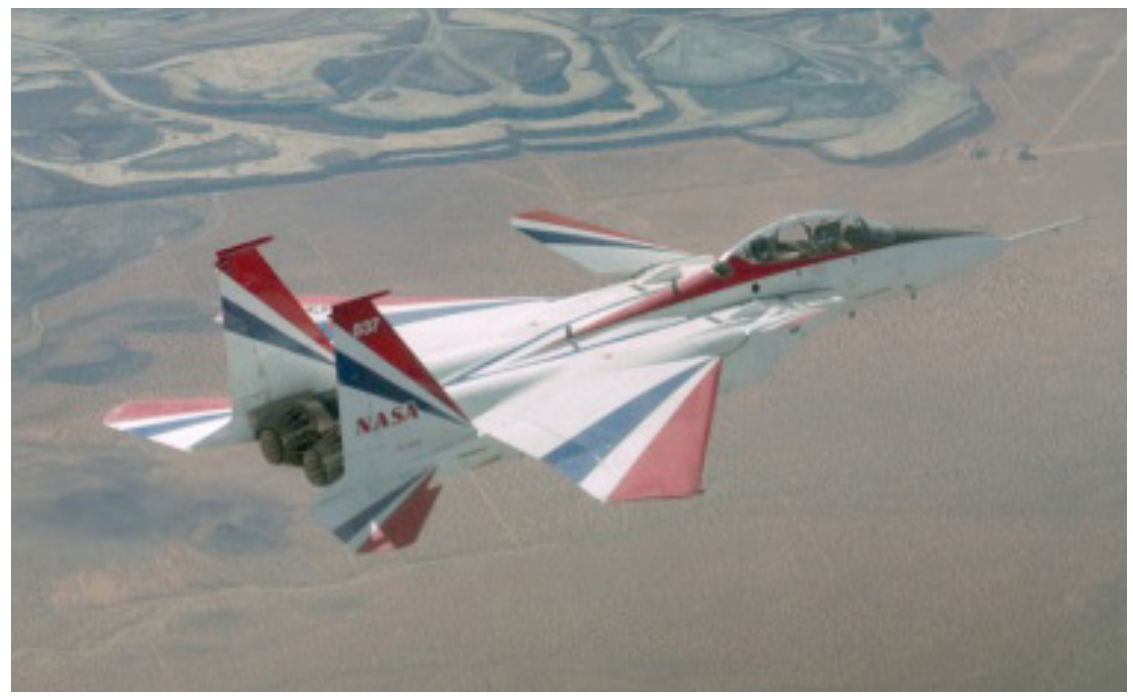

Figure 1. The NASA NF-15B research aircraft, tail number 837.

\section{B. Description of the Intelligent Flight Control System}

The F-15 IFCS is a direct adaptive neural-network-based flight control system. The approach is based on the augmented model inversion architecture developed by Calise, et al., ${ }^{2}$ and Rysdyk, et al. ${ }^{3}$ The general control scheme consists of a dynamic inversion controller with explicit model following. ${ }^{4}$ An adaptive component is added to accommodate large errors that are outside the normal robustness range of the dynamic inversion controller. The neural network providing the online adaptation within the F-15 IFCS scheme is known as a sigma-pi neural network and was developed at the NASA Ames Research Center, Moffett Field, California. ${ }^{5}$ A more detailed description of the implementation of the neural network for flight-testing can be found in Ref. 6 . The main components of the controller are illustrated in Fig. 2.

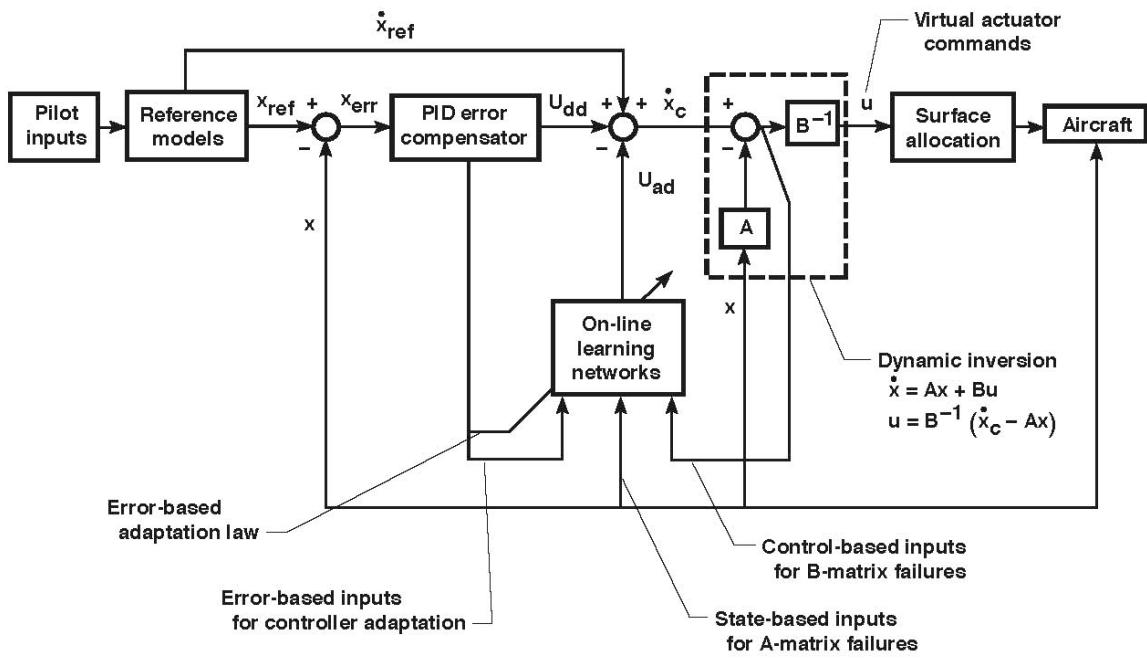

Figure 2. IFCS control architecture.

American Institute of Aeronautics and Astronautics 


\section{Dynamic Inversion}

The dynamic inversion portion of the flight control system provides a consistent controlled response for angular acceleration commands ( $\dot{x}_{c}$ in Fig. 2 ) to the airplane. The primary feedback signals are pitch rate, roll rate, angle of attack, and lateral acceleration. Bank and pitch attitude angle measurements are used for gravity compensation and a sideslip acceleration (betadot) estimation. A simplified onboard aerodynamic model (contained in the A and B matrices in Fig. 2) is incorporated into the control algorithm. For a given commanded acceleration, simplified equations of motion are used to calculate the required control surface commands. A proportional, integral, and derivative (PID) error feedback compensator is wrapped around the dynamic inversion controller to account for the simplifications used in the dynamic model and to reject disturbances.

\section{Explicit Model-Following}

An explicit model-following scheme is used to achieve desired handling qualities. Reference models are defined with desired frequency and damping characteristics. The control system attempts to force the response of the airplane to match the reference model. The pitch axis desired reference model is a second order system and is represented in Eq. (1):

$$
\frac{q_{r e f}}{\delta_{s t k} l o n}=\frac{K_{l o n} \omega_{s p}{ }^{2}\left(s+L_{\alpha}\right)}{s^{2}+2 \zeta_{s p} \omega_{s p} s+\omega_{s p}{ }^{2}}
$$

The short period natural frequency $\left(\omega_{s p}\right)$, damping $\left(\zeta_{s p}\right)$, and apparent lift curve slope $\left(L_{\alpha}\right)$ are selected to achieve Level 1 flying qualities. The longitudinal stick command gain $\left(K_{l o n}\right)$ is chosen to provide an appropriate stick force per unit normal load factor $(g)$.

The roll axis reference model is first order and is shown in Eq. (2):

$$
\frac{p_{\text {ref }}}{\delta_{\text {stk }} \text { lat }_{1}}=\frac{K_{\text {lat }}}{\tau_{r} s+1}
$$

The lateral stick command gain $\left(K_{l a t}\right)$ is chosen to provide the appropriate amount of roll rate for the given flight conditions, and the roll mode time constant $\left(\tau_{r}\right)$ is selected to adjust how fast the roll rate is achieved. Values for these quantities were selected to achieve Level 1 flying qualities.

\section{Adaptive Neural Network}

The goal of the neural network system is to accommodate large errors that are not anticipated in the nominal control law design. A well-designed flight control system is robust to a fairly large range of uncertainty or changes in airplane behavior. As the changes become more extreme the performance degrades. An adaptive system has the ability to readjust the controller to re-achieve desired performance or regain robustness about the new point. In the case of a failure (for example, degraded aircraft dynamics or reduced control surface effectiveness) larger-thanexpected errors will develop. The adaptive neural networks operate in conjunction with the measured response error of the control system. Weights (gains) on the neural network parameters are dynamically adjusted until the error is reduced. The weights act as adjustments to the proportional, integral, and forward-loop gains (note that the weights do not directly adjust the gains, however, a parallel path is mathematically equivalent to changing these gains). Weights can also provide a control bias, a new feedback to the system, or new crossfeed paths between the control axes. When optimal weights are achieved, the feedback error is minimized and the system achieves better reference model following and, presumably, better handling qualities.

The F-15 IFCS implementation incorporated a simplified sigma-pi neural network (Figs. 3 to 5, and Ref. 6). The neural network is essentially the sum of the products of the inputs and a set of weights. Three separate neural networks provided adjustment to the roll, pitch, and yaw forward path commands ( $U_{a d}$ in Fig. 2). Dead zones were applied to the inputs to the neural network learning. These dead zones were used to keep the neural networks from constantly adapting to small errors. The sizes of the dead zones were determined by using the six-degree-of-freedom software simulation. Moderately aggressive maneuvers were flown and the dead zone values were set to 120 percent of the observed errors. Limits were also placed on the weight magnitudes. These weight limits helped provide a limited authority system for initial flight-test purposes. Figures 3 to 5 show the pitch, roll, and yaw neural networks. The specific inputs to each neural network and their associated weights are shown. 


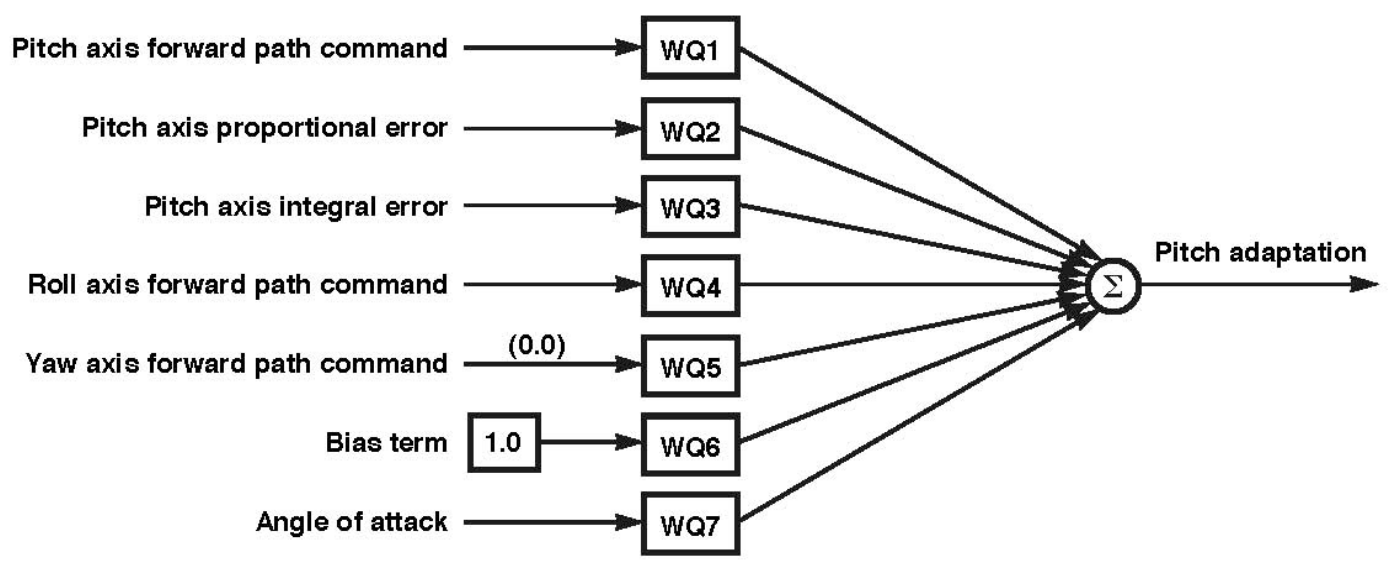

Figure 3. Pitch axis simplified sigma-pi neural network.



Figure 4. Roll axis simplified sigma-pi neural network.

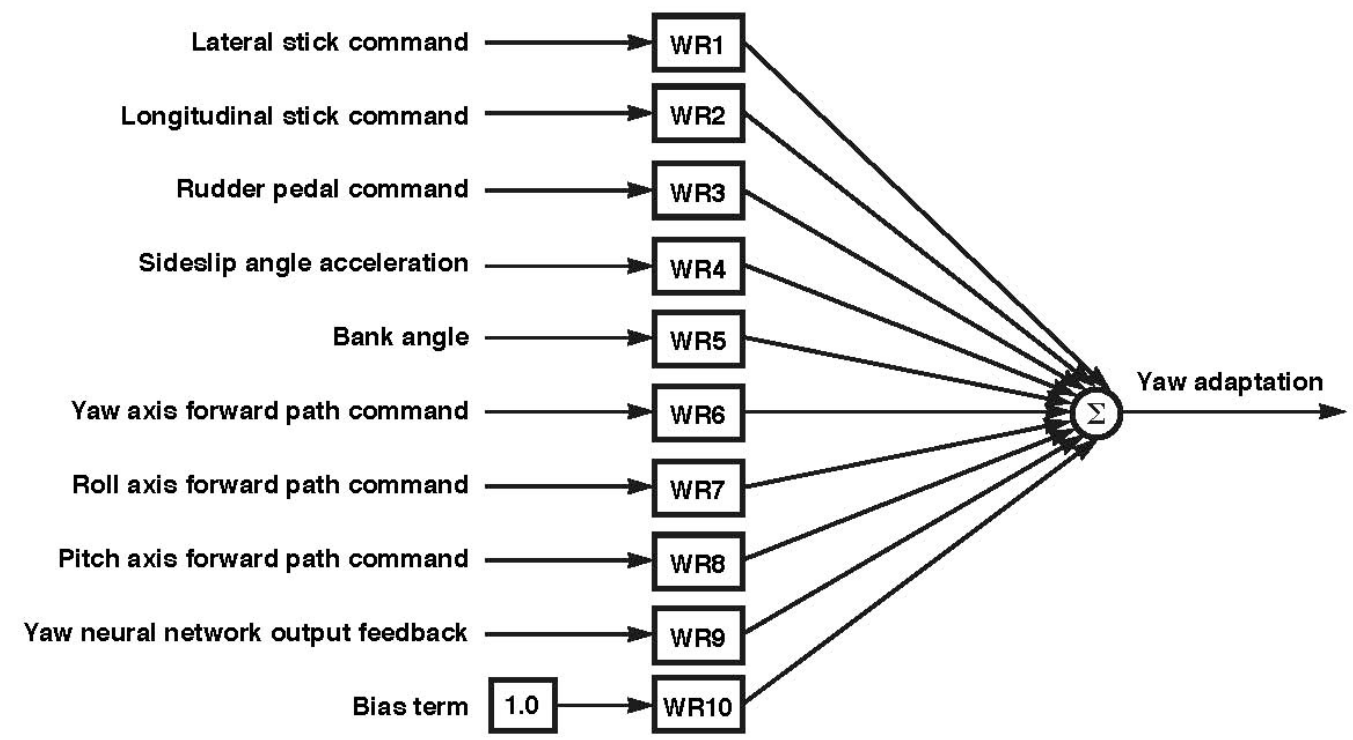

Figure 5. Yaw axis simplified sigma-pi neural network. 
The neural network weights were adjusted using the learning rule $5^{5}$ shown in Eq. (3):

$$
\dot{W}=-G\left(U_{e r r} B_{a}+L U_{e r r} W\right) d t
$$

where $\mathrm{W}$ is the neural network weight vector, $\mathrm{G}$ is the adaptation gain vector, $\mathrm{L}$ is the error-modification term vector, $U_{e r r}$ is the error compensation vector, $B_{a}$ is the basis function vector, and $d t$ is the iteration time step $(0.0125 \mathrm{~s})$. When elements of the error vector $\left(U_{e r r}\right)$ exceed a dead zone threshold, the corresponding weight is adjusted until the error is reduced below the threshold.

\section{Simulated Stabilator Failure}

A simulated stuck stabilator failure mode was developed as a test for the adaptive system. The left stabilator surface was commanded to a fixed value. The value was determined as the trim command with a bias. Biases tested were $0,-2$ and -4 deg. The -2 and -4 deg biases provided an initial transient when the failure was initiated. After the initial transient the flight control integrators (and the neural networks when engaged) retrimmed the airplane using the remaining active flight control surfaces. After the retrimming, simulation and flight-test results showed that the vehicle dynamic response for the three simulated failures was essentially the same for small amplitude maneuvering. With the larger simulated stabilator failures, the retrimmed airplane resulted in control surfaces closer to the position limits. Larger amplitude maneuvers such as full-stick rolls were more likely to produce surface position saturation for the larger simulated stabilator failures; however, for the formation flight evaluations discussed in this report, and in terms of transfer function analysis, the dynamic response of the airplane for the three failure sizes are indistinguishable. Because of this, the same predicted transfer function response is used for all three simulated failures.

\section{Approach}

A series of flight evaluations was performed to test the effectiveness of the adaptive system. Two test pilots performed formation flight evaluations. ${ }^{7}$ The evaluations were accomplished with the baseline IFCS, with simulated failures, and finally with simulated failures and adaptation. Cooper-Harper handling qualities pilot ratings (CHR) were collected for each test.

The results from flight-test are compared to dynamic predictions from a linear model. The linear model was obtained by linearizing a model that included a detailed representation of the control system. Because both the simulated failure and the neural network introduce crossfeeds between the pitch and the lateral-directional axis, the model is higher order than would normally be used. This model was validated by comparison with the full nonlinear six-degree-of-freedom simulation.

To obtain a linear response from the neural network, the weights were held to constant values. The values used were those recorded at the conclusion of the formation flight task.

\section{A. Technical Performance Metrics}

From the pilot's perspective, the relationship between control stick input and airplane response determines the handing qualities of the airplane. For normal in-axis response (that is, roll response due to lateral stick, and pitch response due to longitudinal stick) the desire is to track the previously described onboard reference model. The handling qualities community has defined a region of maximum unnoticeable added dynamics (MUAD) ${ }^{8-10}$ Flighttesting has shown that if the system response is within the MUAD envelope the response is indistinguishable from the lower-order system. Thus, one metric used to assess the effectiveness of the adaptation system was to show how well the system with adaptation compared to the MUAD envelope.

For the off-axis control (that is, roll response due to pitch stick, and pitch response due to roll stick) it is desired that the response be minimized. Ideally, there should be little to no coupling between these axes. There are no wellestablished criteria for how much this coupling needs to be reduced. For the F-15 IFCS we can compare the coupling levels with and without adaptation to show that an improvement was made; however, better numerical metrics are needed not only to assess the effectiveness of the adaptation but to also quantify the severity of the failure.

\section{Results}

Pilot-generated frequency sweeps were used to measure the dynamic response of the F-15 IFCS in flight. These data provided a comparison with simulation-predicted response. Pilot comments and CHR from the formation flight task provided an assessment of how well the adaptive system was performing. The neural network weights measured 
from flight were used with the linear model to analyze and understand the flight results. This section discusses significant results from the flight data analysis.

\section{A. Effect of the Simulated Failure}

Figure 6 shows the frequency response of pitch rate due to longitudinal stick. The onboard reference model transfer function (Eq. 1) and the MUAD envelope are shown. The linear model predicts that the nominal response of the F-15 IFCS lies within the MUAD boundary. With a simulated stabilator failure and no adaptation, the response deviates from the desired onboard model. The flight-measured frequency response is also shown. The flight data were obtained from a pilot-generated frequency sweep and show that the linear model provides a good representation of the response of the airplane.

Figure 7 shows the frequency response of roll rate due to lateral stick. The onboard reference model transfer function (Eq. 2) and the MUAD envelope are shown. Again, note that the simulated stabilator failure moves the frequency response outside the MUAD region and the linear model is a fairly good representation of the flightmeasured response.

Figure 8 shows the frequency response of roll rate due to longitudinal stick. The figure shows that the simulated stabilator failure introduces a significant amount of undesired roll coupling. Comparing Fig. 8 with Fig. 6 shows that there is actually more roll rate response due to longitudinal stick than there is pitch rate response. The flightmeasured response shows good correlation with the linear model. Similarly, Fig. 9 shows the coupling from roll stick to pitch rate. The match of the linear model with flight data is not as good for this transfer function, especially at the lower frequencies.
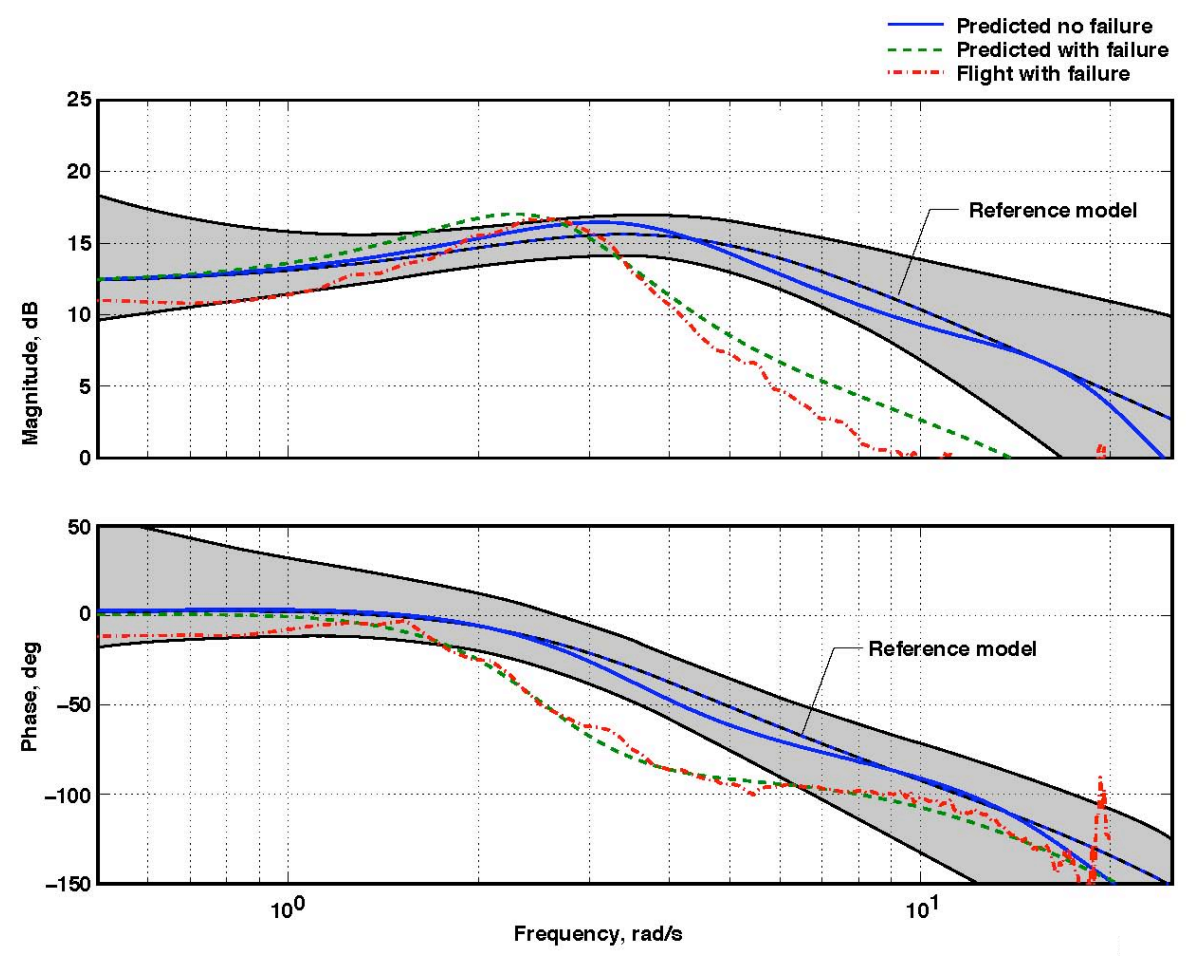

Figure 6. Effect of simulated failure on pitch rate due to longitudinal stick, no adaptation. 



Figure 7. Effect of simulated failure on roll rate due to lateral stick, no adaptation.
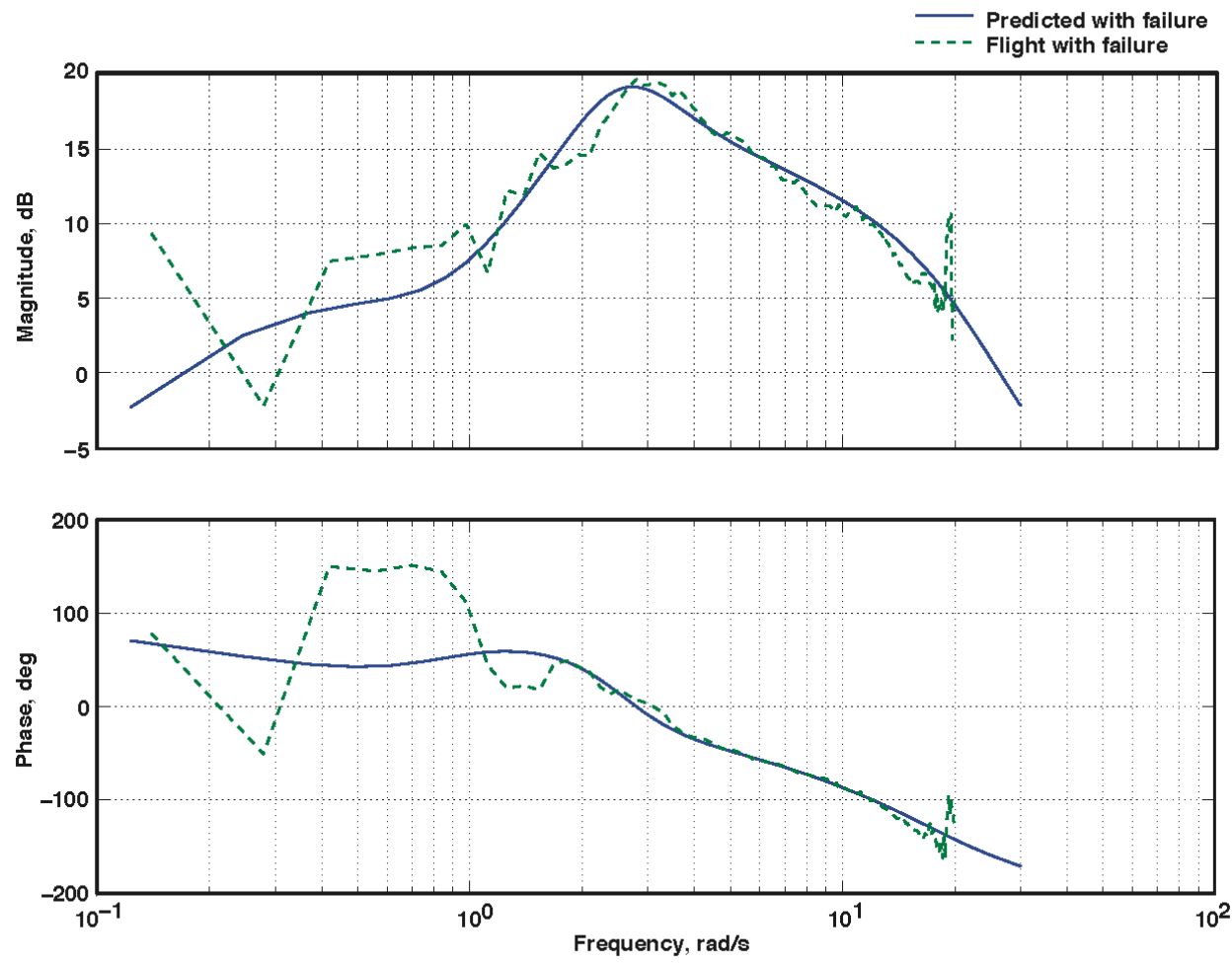

Figure 8. Roll rate due to longitudinal stick with simulated stabilator failure, no adaptation. 

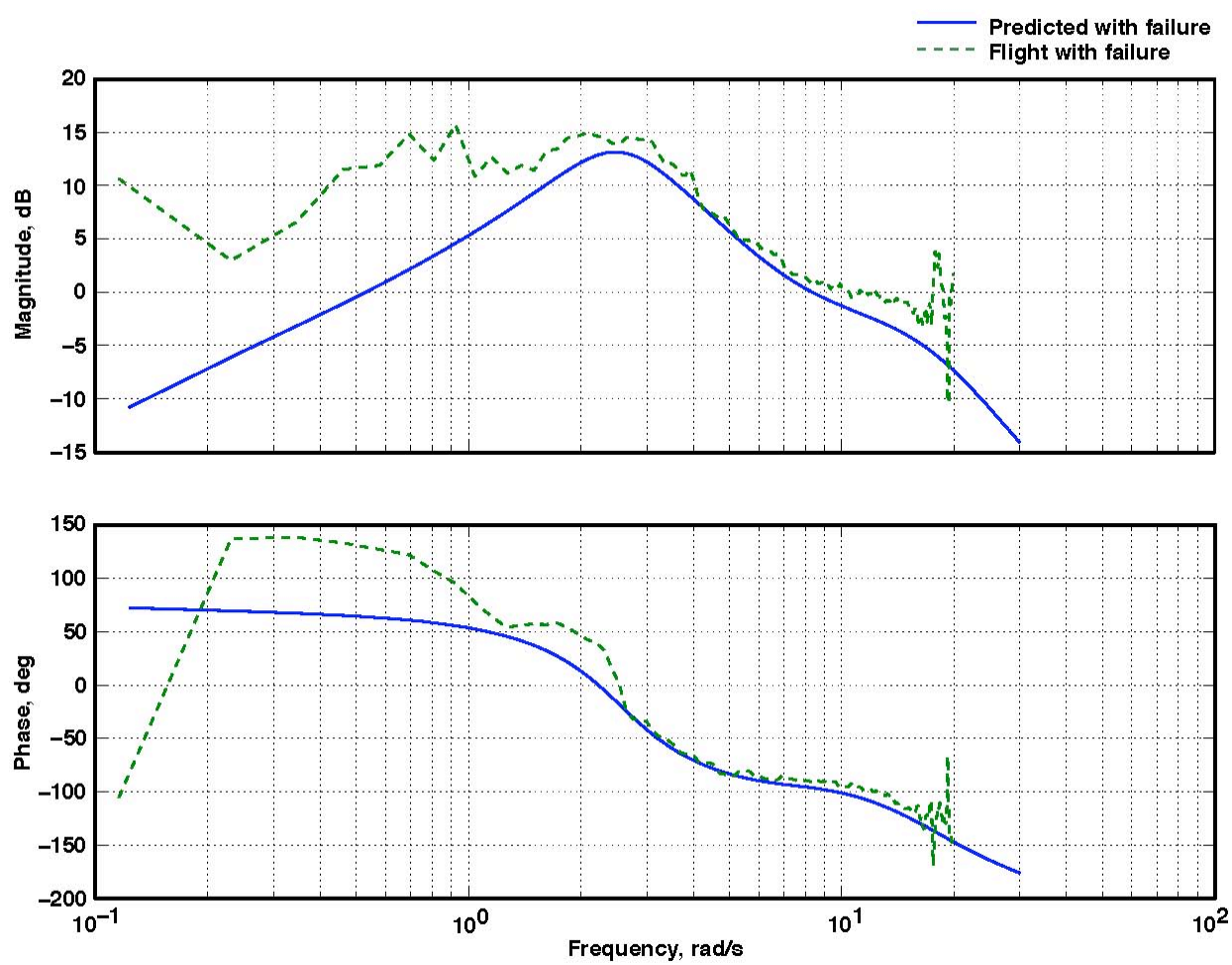

Figure 9. Pitch rate due to lateral stick with simulated stabilator failure, no adaptation.

\section{B. Baseline Formation Flight}

A formation flight task was performed to obtain CHR for the F-15 IFCS. ${ }^{7}$ Table 1 shows the ratings obtained from the two project pilots. The task was performed many times with no simulated failures and no adaptation and was used to gauge the effectiveness of the adaptation. Both pilots consistently rated the airplane as having solid Level 1 handling qualities (CHR less than 4).

Table 1. Pilot ratings with no adaptation and no simulated stabilator failures in $1 \mathrm{~g}$ formation flight.

\begin{tabular}{|l|c|c|c|c|}
\hline $\begin{array}{l}\text { Stabilator failure } \\
\text { magnitude }\end{array}$ & Pilot & $\begin{array}{c}\text { Gross } \\
\text { acquisition } \\
\text { CHR }\end{array}$ & $\begin{array}{c}\text { Fine } \\
\text { tracking } \\
\text { CHR }\end{array}$ & PIO rating \\
\hline Baseline no failure & $\mathrm{A}$ & 2 & 2 & 1 \\
\hline Baseline no failure & $\mathrm{B}$ & 3 & 2 & 2 \\
\hline
\end{tabular}

\section{Formation Flight with Simulated Stabilator Failures}

The CHR for the formation flight task with the simulated stabilator failure are shown in Table 2. Early in the test series Pilot A performed the formation flight task with the zero-degree-from-trim simulated stabilator failure. The pilot's comments indicated that the simulated stabilator failure had a large negative effect on the handling qualities:

“... [there's] definitely some PIO tendency there. Okay, feeling it out, out here at distance, I can already see that it's real unpredictable in pitch. It's going to get interesting when we get the big failures. Okay, I'm going to move in and try to do some fine tracking here. There's a little PIO right there outside of tolerances - wow - getting it settled down there but you have to be very careful about stick inputs, you can over-control it. I'm really having to stay out of the loop. A real huge PIO tendency and there's some coupling there. I keep kind of rolling in. I'm meeting desired results there, but it's taking a great deal of pilot compensation. Let's do a correction low; [then a] correction up. Okay.... a little PIO, I don't know if you guys are seeing that, but boy." 
Table 2. Pilot ratings with no adaptation and simulated stabilator failures in $1 \mathrm{~g}$ formation flight.

\begin{tabular}{|l|c|c|c|c|}
\hline $\begin{array}{l}\text { Stabilator failure } \\
\text { magnitude }\end{array}$ & Pilot & $\begin{array}{c}\text { Gross } \\
\text { acquisition } \\
\text { CHR }\end{array}$ & $\begin{array}{c}\text { Fine } \\
\text { tracking } \\
\text { CHR }\end{array}$ & PIO rating \\
\hline 0 deg from trim (1st time) & A & 6 & 5 & 4 \\
\hline 0 deg from trim (2nd time) & A & 3 & 3 & 3 \\
\hline 0 deg from trim & B & 4 & 4 & 4 \\
\hline-2 deg from trim & A & 2 & 3 & 2 \\
\hline-2 deg from trim & B & 4 & 3 & 2 \\
\hline-4 deg from trim & A & 3 & 3 & 2 \\
\hline-4 deg from trim & B & 4 & 3 & 2 \\
\hline
\end{tabular}

At the time of this rating, Pilot A had little flight time with the simulated stabilator failures. The testing was interrupted before the neural-network-engaged test could be accomplished. Pilot A revisited the same simulated failure on a later test date with the same formation flight task. This time the ratings were much more favorable. Subsequent ratings by both pilots were disappointingly benign. The expectation was that the simulated stabilator failures would provide significantly degraded handling qualities, leaving the adaptation with room for significant improvement. The ratings do reflect some degradation as a result of the simulated stabilator failure.

The change in ratings indicates that familiarity with the simulated stabilator failures allowed the pilots to learn how to better fly the airplane with the failure. During the formation tracking task the pilot was unconsciously using a diagonal stick input to maintain what is essentially a pitch axis task. This diagonal input changes the coupling between the longitudinal and lateral-directional axes. Additionally, it correlates some of the airplane responses (for example, pitch rate with roll rate) and could affect how the neural network weights are adjusted.

\section{Formation Flight with Adaptation}

The CHR given for the formation flight task with the neural network adaptation engaged are shown in Table 3. In general, there was no consistent improvement resulting from the adaptation. Comments generally indicated that the pitch response was improved but the adaptation seemed to introduce a roll pilot-induced oscillation (PIO) tendency.

Table 3. Pilot ratings with adaptation on and simulated stabilator failures in $1 \mathrm{~g}$ formation flight.

\begin{tabular}{|l|c|c|c|c|}
\hline $\begin{array}{l}\text { Stabilator failure } \\
\text { magnitude }\end{array}$ & Pilot & $\begin{array}{c}\text { Gross } \\
\text { acquisition } \\
\text { CHR }\end{array}$ & $\begin{array}{c}\text { Fine } \\
\text { tracking } \\
\text { CHR }\end{array}$ & PIO rating \\
\hline 0 deg from trim & A & 3 & 3 & 4 to 3 \\
\hline 0 deg from trim & B & 4 & $4 / 7^{*}$ & $2 / 4^{*}$ \\
\hline-2 deg from trim & A & 2 & 2 & 1 \\
\hline-2 deg from trim & B & 3 & $4 / 7^{*}$ & $2 / 5^{*}$ \\
\hline-4 deg from trim & A & 3 & 3 & 2 \\
\hline-4 deg from trim & B & 4 & $4 / 4^{*}$ & $2 / 2^{*}$ \\
\hline
\end{tabular}

* Rating divided into longitudinal/lateral.

\section{E. Roll Pilot-Induced Oscillation}

From the pilot ratings shown in Table 3, the first thing that stands out is that Pilot B rated the lateral axis fine tracking with a CHR of 7 for the 0 and -2 deg-from-trim stabilator failures. Pilot B's comments indicated that he experienced lateral PIO for these cases. It is also interesting to note that with the same pilot the lateral axis fine tracking with -4 deg-from-trim stabilator failure earned a CHR of 4 and no PIO was encountered. Pilot A did not experience any PIO during this formation flight task and generally gave more favorable ratings than did Pilot B. As was mentioned earlier, after the initial transient, the dynamic response without adaptation for these three failures should be very similar. The occurrence of the PIO indicates that the adaptation might be introducing differences that are perceived by the pilot. 
Figure 10 shows a typical time response for the formation flight tracking task. The pitch axis neural network weights are shown. The change in weights at approximately $1 \mathrm{~s}$ is because of the transient caused by the simulated failure. The pilot starts with moderately aggressive tracking at approximately $30 \mathrm{~s}$. As he increases aggressiveness at approximately $50 \mathrm{~s}$ some further adjustment of the neural network weights is observed. At approximately $60 \mathrm{~s}$ the weights have settled to fairly constant values. The weights are normalized to $+/-1.0$ using their weight limit values. As Fig. 10 shows, most of the weights stayed within limits. WQ1 actually reached its negative limit $(-0.5)$. This weight limiting might affect the degree to which the system can regain pitch tracking performance and will be discussed below.
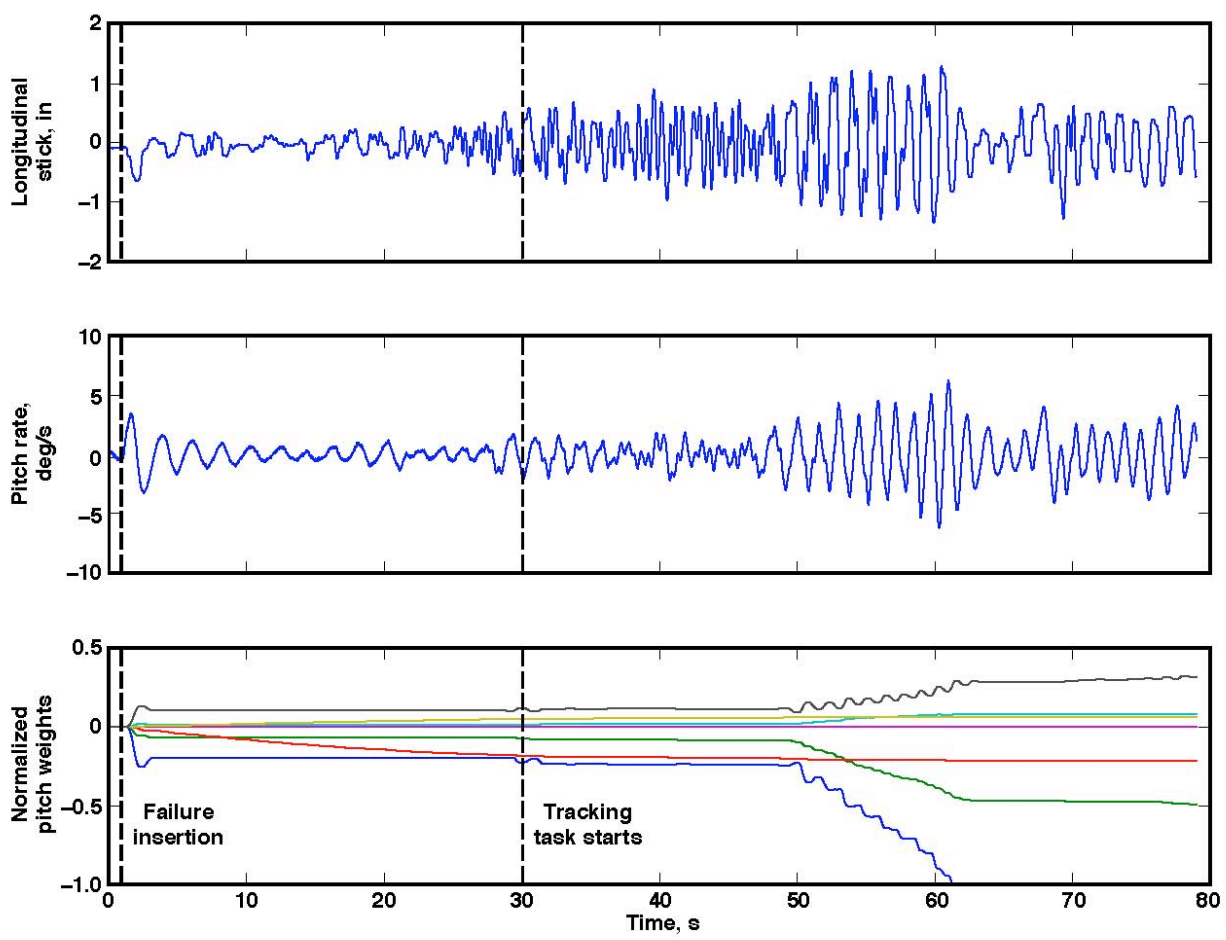

Figure 10. Typical formation flight time history.

To understand the differences perceived by the pilots for the formation flight tasks, these flight-measured weight values and a linear model were utilized. The neural network weights at the end of the tracking task were recorded and held constant in the linear model. Transfer functions of this fixed gain system were then computed. Figure 11 shows the roll rate due to roll stick transfer function with neural network weights measured from flight for the six formation flight tests. The two cases in which Pilot B rated the lateral axis with a CHR of 7 stand out with a sharp gain roll-off beginning at 4 to $5 \mathrm{rad} / \mathrm{s}$. These two cases exhibit unconventional roll response. A "normal" airplane has a first-order roll response. These two cases definitely exhibit higher-order response.

Figure 12 shows the pitch rate due to roll stick frequency response for the same formation flight tasks. Again the two PIO cases stand out. For this plot, the two cases have a phase angle that is 180 deg different from the other cases. This means that the phasing of the coupling between the roll stick and pitch rate is of opposite sign. Since there are no well-established criteria for asymmetric behavior it is not known if this phase difference contributes to the PIO tendency.

To better understand the root cause of the unconventional roll response, the -2 deg stabilator failure flown by Pilot B was examined. It was found that by far the largest contributor to the unusual roll response was the pitch neural network weight number 4 (WQ4). The WQ4 weight provided a roll feedback into the pitch axis. Using the linear model, the frequency response was recomputed with two variations to the flight-measured neural network weight values. These two cases are shown in Table 4. For case 1, the WQ4 weight was set to zero. Figure 13 shows that when the WQ4 weight is set to zero, the roll response looks more conventional. The main beneficial effect of WQ4 is to reduce the undesired coupling of pitch response due to roll stick. Figure 14 shows the loss in attenuation of the pitch response due to roll stick when the WQ4 weight is set to zero. Figure 14 also shows that the WQ4 weight contributes to the phase change observed in Fig. 12. 



Figure 11. Roll rate due to roll stick formation flight task with adaptation.

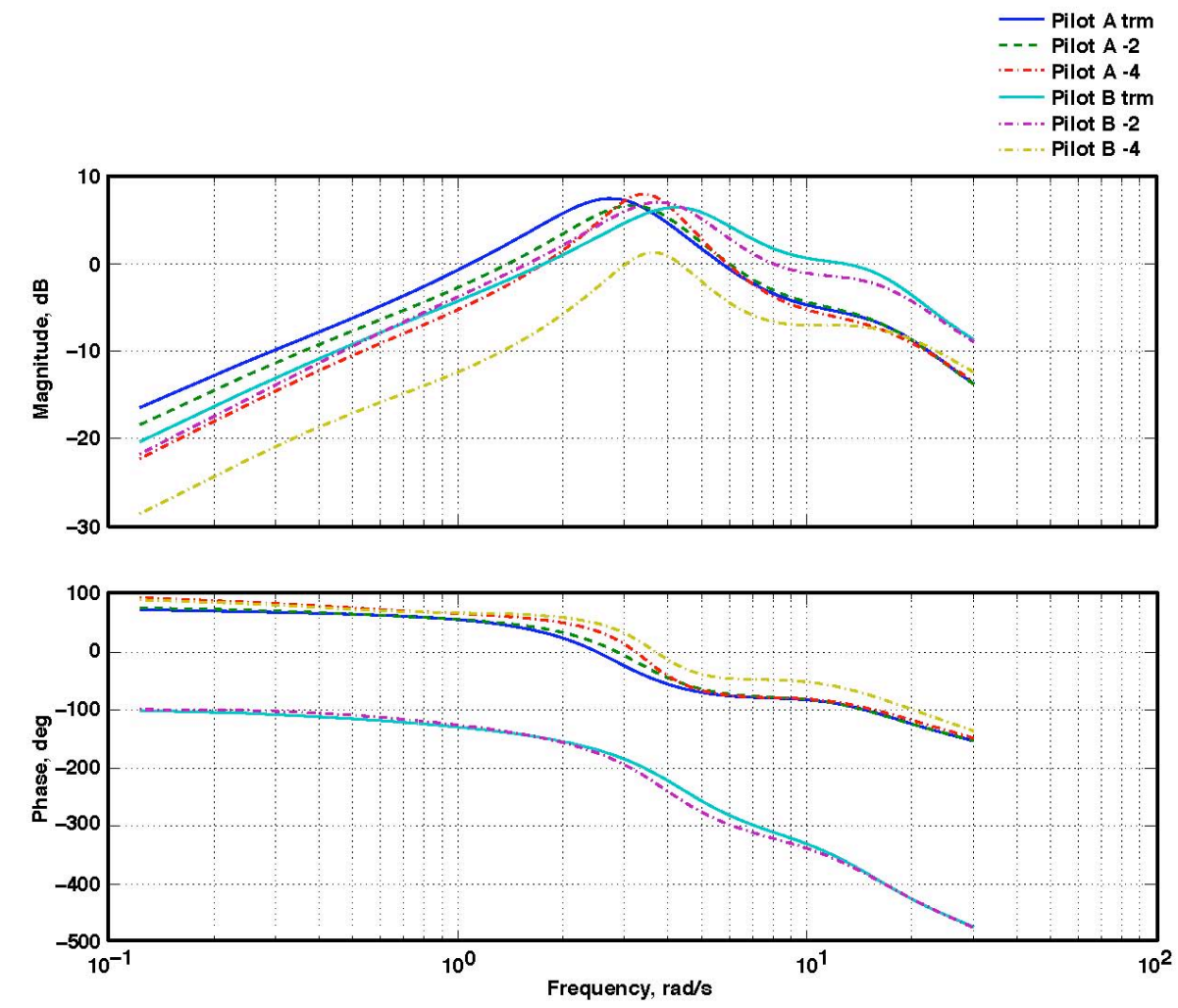

Figure 12. Pitch rate due to roll stick formation flight task with adaptation. 

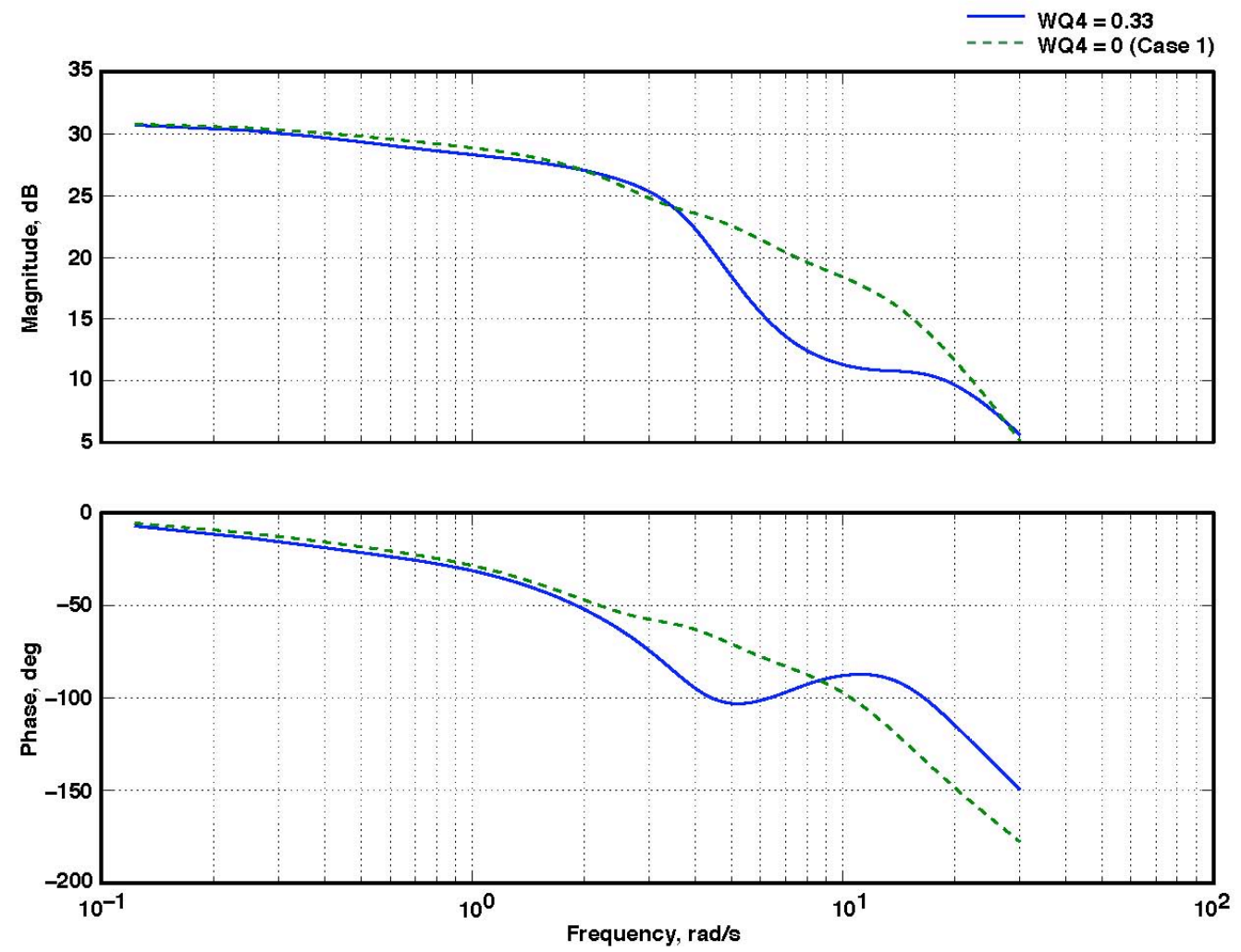

Figure 13. Case 1 roll rate due to roll stick, Pilot B: 2 deg stabilator failure.
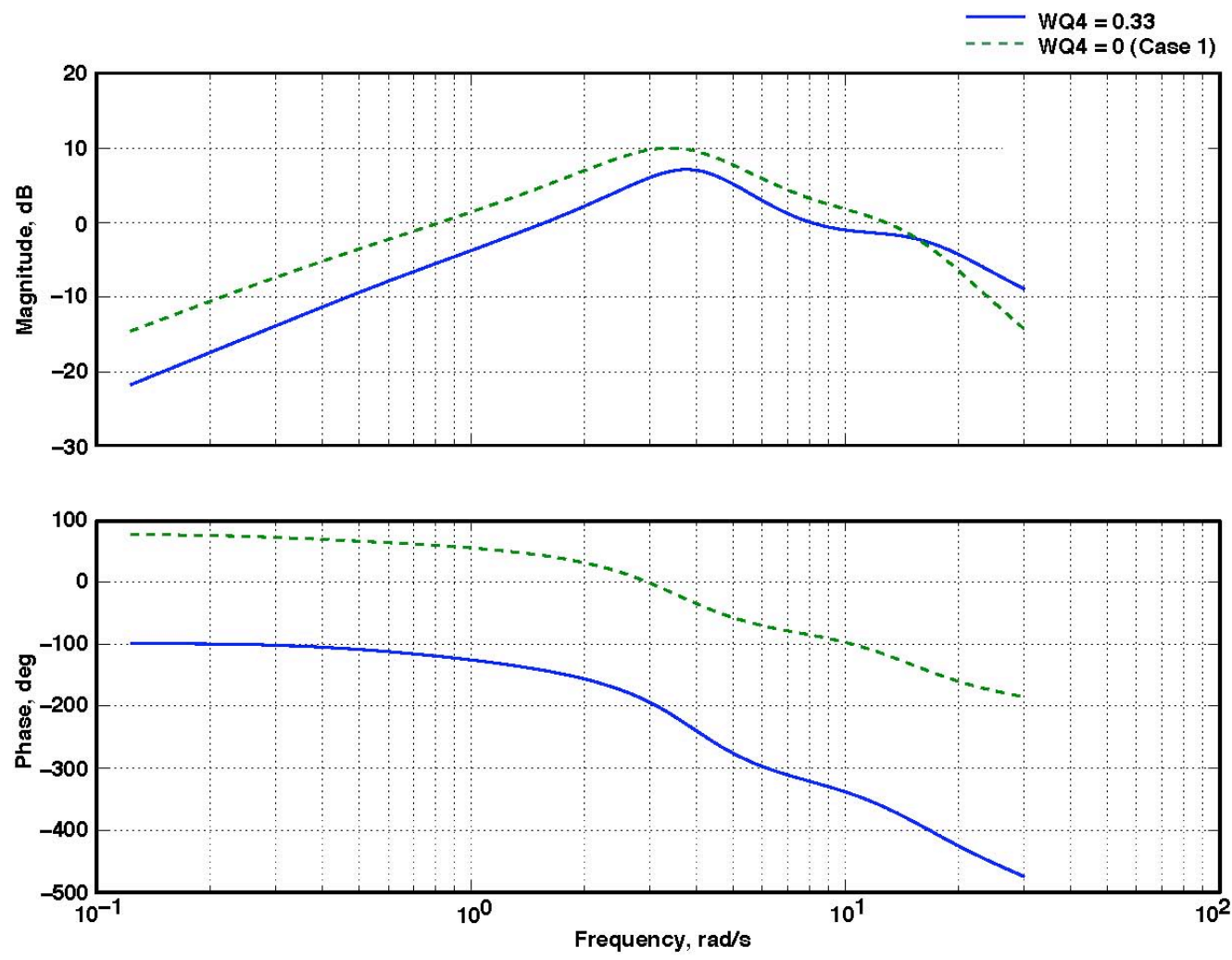

Figure 14. Case 1 pitch rate due to roll stick, Pilot B: 2 deg stabilator failure. 
Table 4. Test cases for -2 deg simulated stabilator failure using variations in the neural network weight values.

\begin{tabular}{|c|c|c|c|}
\hline $\begin{array}{c}\text { Neural network weight } \\
\text { (important weights shown) }\end{array}$ & $\begin{array}{c}\text { Flight- } \\
\text { measured } \\
\text { values }\end{array}$ & $\begin{array}{c}\text { Case 1 } \\
\text { WQ4 = 0 }\end{array}$ & $\begin{array}{c}\text { Case 2 } \\
\text { WP1 }=\mathbf{0 . 5}\end{array}$ \\
\hline WP1 & -0.15 & -0.15 & $-\mathbf{0 . 5 0}$ \\
\hline WP2 & -0.04 & -0.04 & -0.04 \\
\hline WP3 & -0.50 & -0.50 & -0.50 \\
\hline WP4 & 0.86 & 0.86 & 0.86 \\
\hline WQ1 & -0.50 & -0.50 & -0.50 \\
\hline WQ2 & -0.25 & -0.25 & -0.25 \\
\hline WQ3 & -0.11 & -0.11 & -0.11 \\
\hline WQ4 & 0.33 & $\mathbf{0 . 0}$ & 0.33 \\
\hline WQ7 & 3.21 & 3.21 & 3.21 \\
\hline
\end{tabular}

The WQ4 weight was highest for the Pilot B trim and -2 deg-from-trim stabilator failure cases. The next highest value for WQ4 was seen on the Pilot B -4 deg-from-trim stabilator failure case; however, for this case, the detrimental effects of the WQ4 weight were offset by WP1. To see how the WP1 weight affects the -2 deg stabilator failure case the linear model was utilized. With all weights set to the flight-measured values, WP1 was increased to -0.5 (the current weight limit) (case 2 in Table 4). Figure 15 shows that with the higher WP1 value the roll response is restored back to what is desired for the -2 deg-from-trim stabilator failure. There is no apparent drawback to a higher WP1 weight. The question is, why didn't the adaptive system adjust this gain upward?
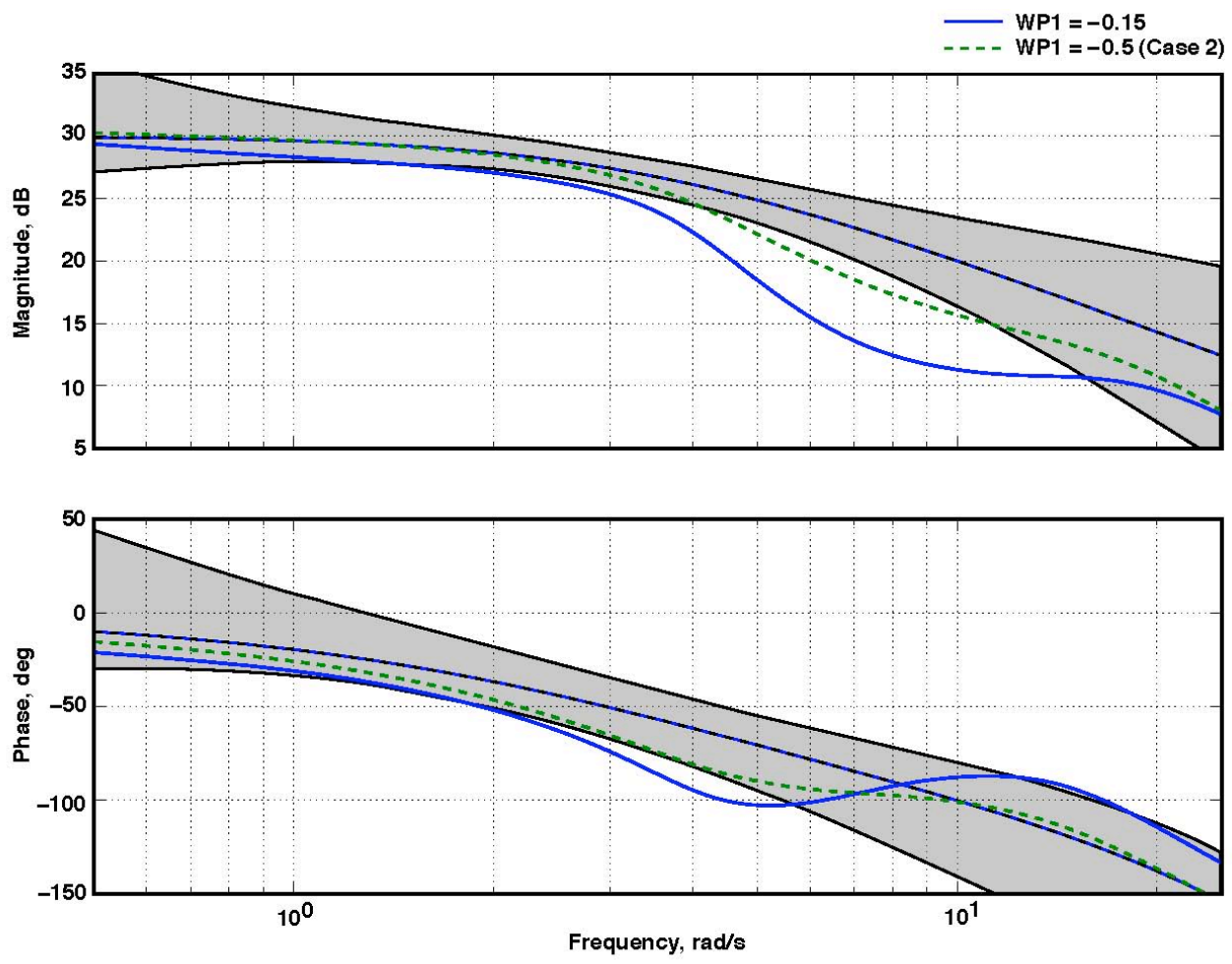

Figure 15. Case 2 roll rate due to roll stick, Pilot B: 2 deg stabilator failure.

Examining the time history of the weights for the formation flight tests shows that the roll neural network weights change very little during the formation flight task. There is an initial adjustment due to the failure insertion. Once the formation flight task starts, there is not enough roll error generated to cause neural network adaptation. Figure 16 shows the error term that feeds into the WP1 weight. A dead zone on this path was added to prevent 
overlearning caused by small errors. The plot clearly shows that the dead zone eliminates all errors generated during the tracking task.
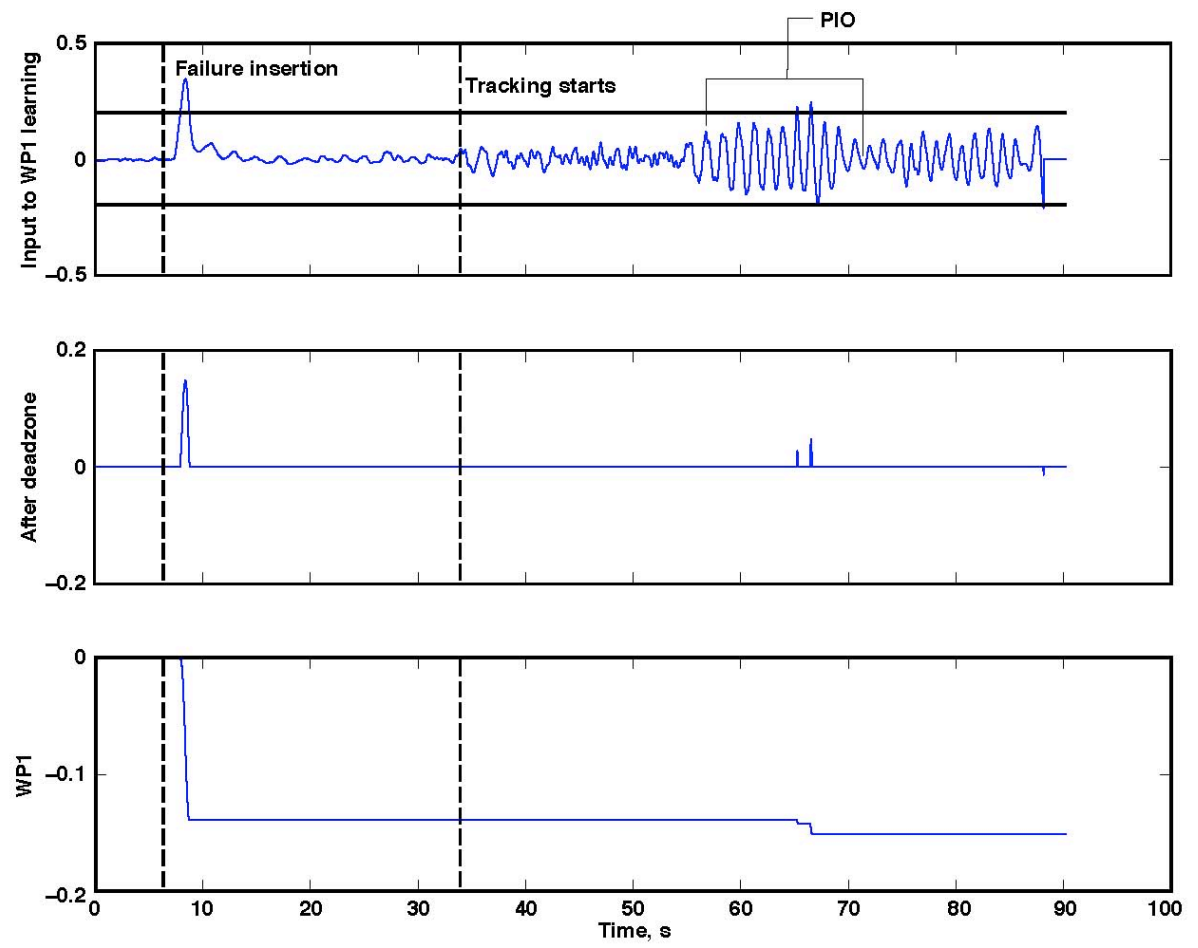

Figure 16. Effect of deadzone on WP1.

The formation flight task is essentially a longitudinal task. Offsets and corrections are made in the pitch axis. Even in the presence of a roll PIO, the roll errors were below the dead zones on the adaptation learning input. These data indicate that the dead zone size needs to be reduced to allow the neural network to respond to the roll PIO, however, reducing the dead zone size must be balanced with the requirement that the system not be too sensitive.

\section{F. Improved Pitch Responsiveness}

For Pilot A and the -2 deg-from-trim stabilator failure there was a noticeable change in flying characteristics as noted by the following comments:

“...actually right now it doesn't look like we have that undesirable motion. Looks like that little bit of fine tracking motion that we were dealing with before is gone and we're looking at a baseline airplane. I don't feel that underlying pitching, you know, oscillation going on. I feel the airplane just a little bit, maybe, just a little bit. There's a little bit of deviation there. Right back into position. A little bit of oscillation now. Let's go ahead and do a gross acquisition task. Okay, [the] airplane actually doesn't feel that sluggish, it feels like it kind of took care of that sluggish feeling. [Back seater agrees that the aircraft feels a lot quicker]. It does, it feels a lot like, more like the baseline airplane...It just doesn't feel as sluggish, it made it more responsive it seems like. I don't feel the coupling and I don't feel that underlying pitching motion."

The longitudinal frequency response using the flight-measured weights for the -2 deg-from-trim stabilator failure case is shown in Fig. 17. With the adaptation on, the frequency response is shifted closer to the desired onboard reference model. Although the response is not within the MUAD region, there is a definite increase in the natural frequency of the system. As Fig. 10 shows, the WQ1 weight generally limits for the formation flight tracking tasks. Possibly with a higher WQ1 weight limit better pitch tracking could be achieved. The observed increase in responsiveness is also confirmed in Fig. 17 by the shift in the gain peak of the response from approximately 2.1 $\mathrm{rad} / \mathrm{s}$ to close to $3 \mathrm{rad} / \mathrm{s}$. The pilot perceives this increase in natural frequency as a more responsive, less sluggish system. 

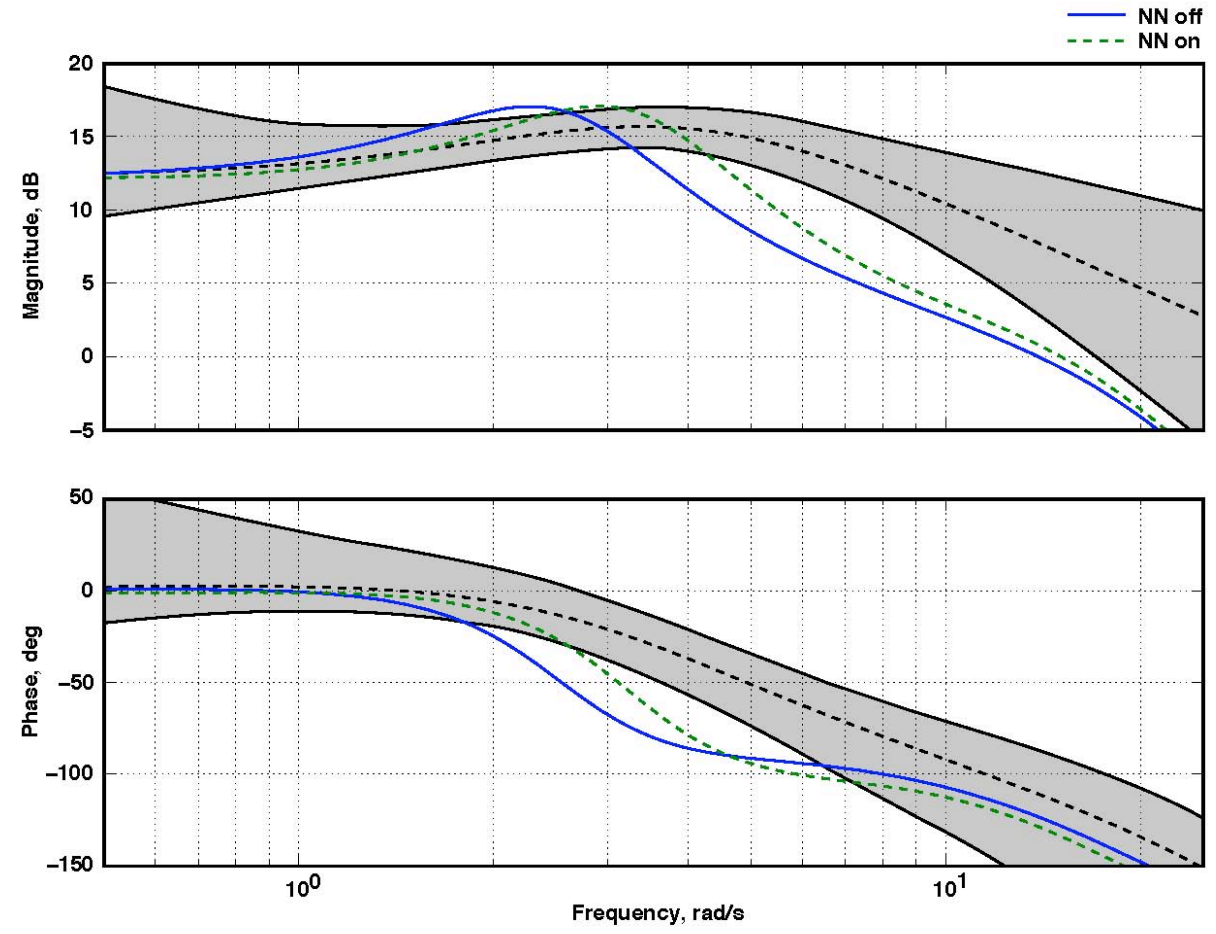

Figure 17. Pitch rate due to longitudinal stick transfer function, Pilot A: -2 deg simulated stabilator failure.

Pilot A also stated, "I don't feel the coupling." Figure 18 shows the roll response due to a longitudinal stick input. The figure indicates that the neural network reduces the amount of unwanted roll response. In the region close to the natural frequency of the system $(3 \mathrm{rad} / \mathrm{s})$ the adaptation provides about $-3 \mathrm{~dB}$ (a 30 percent reduction) of attenuation compared to the nonadapting system.
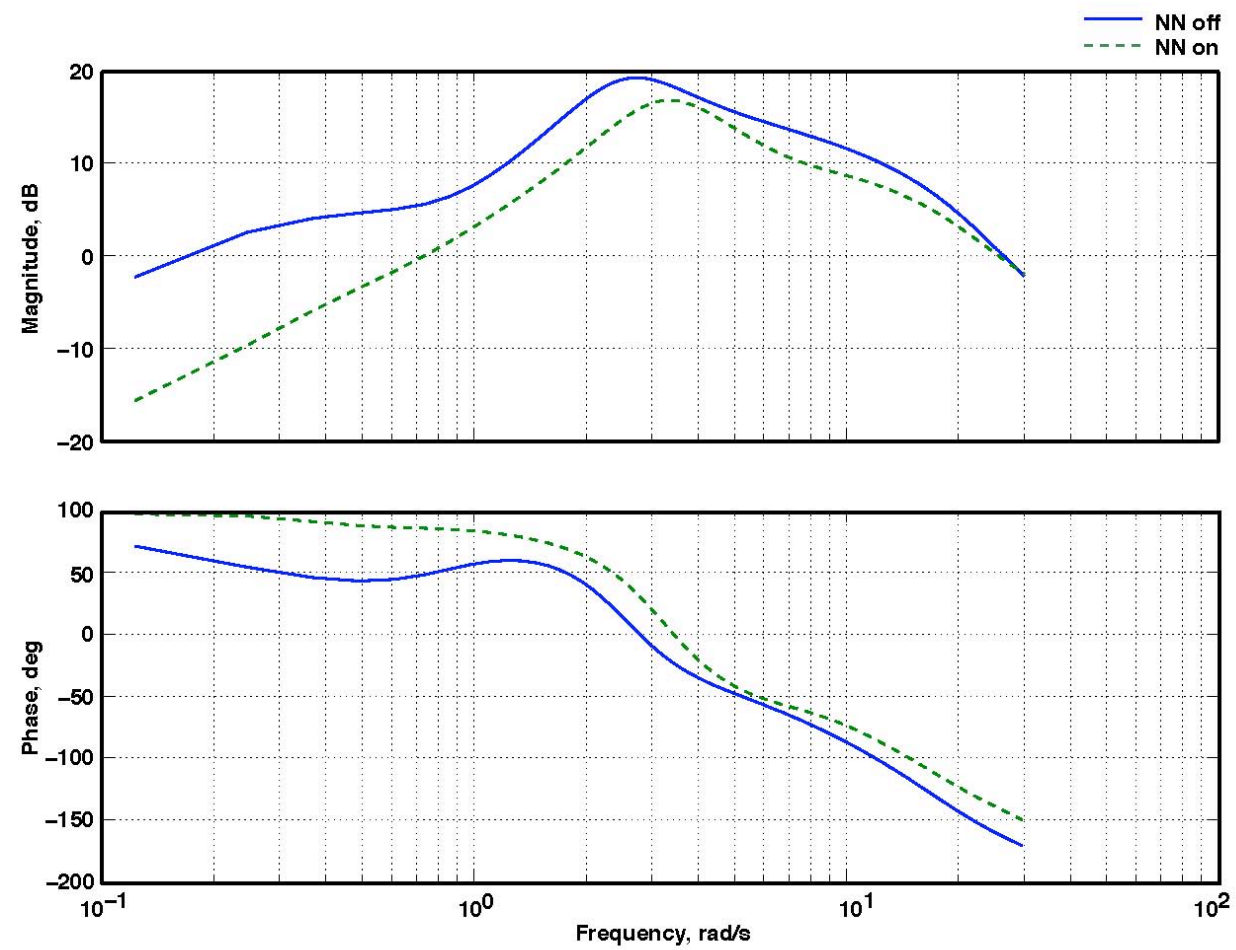

Figure 18. Roll rate due to longitudinal stick transfer function, Pilot A: -2 deg simulated stabilator failure. 


\section{Concluding Remarks}

A direct adaptive neural-network-based flight control system was developed to provide increased resiliency to system failures. A simulated frozen (unmovable) stabilator failure was used to challenge the adaptive system. A piloted handling qualities formation flight task was flown and Cooper-Harper handling qualities ratings were assigned.

The simulated stabilator failure creates a large change in airplane response, altering both the pitch and roll response characteristics. With the simulated stabilator failure, the system without adaptation cannot achieve the desired tracking of the onboard reference model. The simulated stabilator failure also introduces a high level of undesired coupling between the longitudinal and lateral-directional motion of the airplane. The simulated failure causes more roll rate response due to longitudinal stick than there is pitch rate response. Despite the severity of the failure there is some indication that over time the pilots were able to adjust and learn to fly with the simulated failure.

The performance of the adaptation was assessed in terms of its ability to reestablish good model-following in the commanded axis. The ability to suppress the cross-coupling between the roll and pitch axis was also examined. These two goals can sometimes conflict, and it was found that good metrics for the cross-axis coupling were not available. Better cross-coupling numerical metrics are needed not only to assess the effectiveness of the adaptation, but also to quantify the severity of the failure.

With the simulated failures and the adaptation engaged, there was generally improvement in the pitch-rate response; however, a tendency for roll pilot-induced oscillation was experienced. A linear model with fixed neural network weights determined from flight measurements provided a tool to understand the test results. This linear model provided good predictions of the system frequency response when compared with flight data. The linear model allowed for independent variation of the neural network weights so that contributions from individual weights could be better understood.

The two test cases that resulted in a lateral pilot-induced oscillation tendency with the adaptation engaged produced an unconventional roll rate due to roll stick transfer functions. Analysis showed which neural network weight could have corrected this problem. The flight data show that dead zones in the system prevented the adaptation from occurring. These data indicate that the dead zone size needs to be reduced to allow the neural network to respond to the roll pilot-induced oscillation; however, reducing the dead zone size must be balanced with the requirement that the system not be too sensitive.

In some cases, the adaptation provided a noticeable increase in responsiveness in the pitch axis. The neural network weights in this case increased the apparent natural frequency of the closed-loop system. These same weights provided a reduction of approximately $-3 \mathrm{~dB}$ (a 30 percent reduction) in coupling between pitch and roll compared with the nonadapting system.

The F-15 Intelligent Flight Control System provided an initial flight evaluation of a direct adaptive neuralnetwork-based flight control system. Some improvements were noted as well as some detriments. The behavior of the adaptive system was not always consistent. These flight data provide a basis for analysis and understanding of this type of adaptive system; areas of potential improvement have been identified using these data. This flight experience and continued testing will help to push forward adaptive controls technology as an option for future aerospace vehicles. 


\section{References}

${ }^{1}$ Smolka, J.W., Walker, L.A., Johnson, Major G.H., Schkolnik, G.S., Berger, C.W., Conners, T.R., Orme, J.S., Shy, K.S., and Wood, C.B., "F-15 ACTIVE Flight Research Program," 1996 Report to the Aerospace Profession Fortieth Symposium Proceedings, 1996, pp. 112-145.

2 Calise, A.J., Lee, S., and Sharma, M., "Direct Adaptive Reconfigurable Control of a Tailless Fighter Aircraft," AIAA-98-4108, Aug. 1988.

3 Rysdyk, R.T., and Calise, A.J., "Fault Tolerant Flight Control Via Adaptive Neural Network Augmentation," AIAA-98-4483, Aug. 1988.

4 Williams-Hayes, P.S., "Flight Test Implementation of a Second Generation Intelligent Flight Control System," NASA/TM-2005-213669, Nov. 2005.

${ }^{5}$ Kaneshige, J., Bull, J., and Totah, J.J., "Generic Neural Flight Control and Autopilot System,” AIAA-2000-4281, Aug. 2000.

${ }^{6}$ Burken, J.J., Williams-Hayes, P., Kaneshige, J.T., and Stachowiak, S.J., "Reconfigurable Control with Neural Network Augmentation for a Modified F-15 Aircraft,” NASA/TM-2006-213678, Apr. 2006.

${ }^{7}$ Bomben, C.R., Smolka, J.W., Bosworth, J.T., Williams-Hayes, P.S., Burken, J.J., Larson, R.R., Buschbacher, M.J., and Maliska, H.A., "Development and Flight Testing of a Neural Network Based Flight Control System on the NF-15B Aircraft," 2006 Report to the Aerospace Profession Fiftieth Symposium Proceedings, 2006, pp. 214-240.

${ }^{8}$ Wood, J.R., and Hodgkinson, J., "Definition of Acceptable Levels of Mismatch for Equivalent Systems of Augmented CTOL (Conventional Take-off and Landing) Aircraft," McDonnell Aircraft Corporation, Report number MDC A6792, St. Louis, MO, Dec. 1980.

${ }^{9}$ Hoh, R.H., Mitchell, D.G., Ashkenas, I.L, Klein, R.H., Heffley, R.K., and Hodgkinson, J., "Proposed MIL Standard and Handbook - Flying Qualities of Air Vehicles, Volume II: Proposed MIL Handbook," AFWAL-TR-82-3081 Volume II, WrightPatterson Air Force Base, OH, Nov. 1982.

${ }^{10}$ Mitchell, D.G., Hoh, R.H., He, C., and Strope, K., "Determination of Maximum Unnoticeable Added Dynamics," AIAA 2006-6492, Aug. 2006. 